\title{
Sobre Cantos cívicos
}

La obra Cantos cívicos presentada por Miguel Ventura y NILC en el Museo Universitario Arte Contemporá-

En el artículo se discute la obra Cantos cívicos presentada por Miguel Ventura y NILC en el Museo Universitario Arte

Contemporáneo (MuAC) de la UNAM. Debido a la polémica que tal obra suscitó, este texto se da a la tarea de analizar los argumentos presentados en el debate $y$ de proponer un marco teórico filosófico para ponderarlos. El resultado de esta reflexión es la incorporación de categorías estéticas

y filosóficas que permiten la comprensión de la obra más allá del creador y sus intenciones, lo que posibilita hacer frente al tema del nazismo incorporado en Cantos cívicos con una conciencia crítica que no llama inmediata e irreflexivamente a la censura.

Palabras clave: censura, muerte del autor, nacionalsocialismo, Holocausto, Cantos cívicos.

Profesora e investigadora de la Facultad de Filosofía y Letras de la UNAM.

mariantonia@magonzalezvalerio.com Profesora e investigadora de la Facultad de Filosofía y Letras de la UNAM.

rosauramart@hotmail.com neo (MuAC) fue el blanco de una fuerte polémica en relación con el compromiso político de la obra y/o del autor en lo que a la condena del nazismo y los regímenes totalitarios se refiere.

Este ensayo tiene la intención de ser una reflexión en voz alta a propósito del debate suscitado por la obra, el cual deja ver la necesidad de mantener una constante vigilancia sobre los temas de racismo, exclusivismo, discriminación o segregación. La universidad pública ha de ser vigía permanente de cualquier intento de denegar o incluso banalizar esos temas y tiene el cometido de reaccionar con responsabilidad moral e histórica.

La pieza ha suscitado críticas y fuertes reacciones en el medio universitario y en el mundo del arte y no gratuitamente; la polémica está anunciada desde el principio, así como la provocación. Todo lo que aparece en el texto, dice Roland Barthes, es por principio notable, y por ende, susceptible de interpretación 
y sobreinterpretación. En ese sentido, la obra de Ventura aparece claramente como un desafío para el pensar, para la recepción, para la crítica de arte y para quien especta.

¿Cómo comprender la obra y desde dónde? La curaduría ha explicado el contexto de la obra presentada previamente en España, así como el de Miguel Ventura y sus otros proyectos artísticos; la crítica de arte ha explicado el contexto del arte en México, del arte en la UNAM, del MuAC. Pero más allá de eso, surgen los siguientes cuestionamientos: ¿Qué significa una obra que usa como tema principal el nacionalsocialismo en un país como el nuestro? ¿Qué significa la aparición de los textos pro-nazis de Vasconcelos en la revista Timón? ¿Cómo leer el "Por mi raza hablará el espíritu” después de las apologías de Vasconcelos al régimen nazi? ¿Qué hace en un museo universitario una obra que a todas luces denuncia la política de la revista dirigida por el que fuera uno de los rectores más connotados y queridos de la UNAM? Para la historia universitaria parece claramente olvidada esta faceta de Vasconcelos. La obra de Ventura nos la recuerda, y en algunos casos la presenta por primera vez a muchos miembros de la comunidad universitaria. La memoria y el olvido en la creación de próceres nacionales ha sido siempre esencial en este punto; la memoria, el llamado a la memoria es fehaciente. Pero cabe todavía preguntar cuáles son las consecuencias de ello.

Difícil marcar las consecuencias, difícil también pensarlas. Pero en este contexto nos parece meritoria la exposición que hace la pieza de este momento olvidado por la comunidad universitaria. Llama, pues, a la reflexión, y sobre todo, a la necesidad de recordar y no hacer como si lo deleznable del pasado no hubiera existido. Por eso, una obra como Cantos cívicos en un país como el nuestro es claramente un llamado al recuerdo, a la conciencia, a la reflexión.

Así, probablemente, podríamos marcar la intención en la pieza en lo que a su compromiso social y moral se refiere, 
pero eso no es todo. Podríamos también preguntar qué hacen las páginas de sociales de los periódicos mexicanos puestas en un escenario escatológico y presumiblemente grotesco, qué tiene que ver esto con lo anterior, qué tienen que ver los oficiales de la SS con la burla hacia la clase alta mexicana, con la denuncia de la corrupción en el mundo del arte, entre otras cosas. ¿Es posible utilizar un símbolo como la suástica para referirse a multiplicidad de acontecimientos que entre sí no tienen nada que ver? ¿Es en esta relación puesta, impuesta por Cantos cívicos donde se ve lo que la crítica ha cuestionado como falta de responsabilidad moral, social e histórica?

Este tipo de preguntas, entre otras muchas, es el que nos ha suscitado Cantos cívicos. La polémica, no obstante, no ha pasado por estos cuestionamientos de manera contundente. Esto es, lo que se ha puesto a debate no ha sido principalmente los atributos estéticos de la obra, su relación con la historia del arte, su contexto nacional y universitario, el vínculo entre el arte y la ciencia a propósito de las ratas de laboratorio, la estética de lo grotesco y demás temas. Todos estos temas parecen haber sido dejados de lado a favor de la discusión sobre la condena explícita al régimen nazi, el reconocimiento del Holocausto y de sus víctimas judías.

El tema, ya nombrado así, pide un tratamiento por demás serio e informado. Sería ocioso citar aquí la multiplicidad de obras que han hecho alusión al nacionalsocialismo en términos metafóricos que no implican una condena directa del tipo: "Yo, Miguel Ventura, autor de Cantos cívicos, como persona y creador me pronuncio en contra del nazismo y cualquier totalitarismo". No se trata del decir directo del autor, no se trata de la intención del autor; no se trata, en suma, del autor. La actitud de Ventura, su discurso directo y demás son ciertamente criticables y ello en más de un sentido, sin embargo, la discusión en este caso ha de versar sobre Cantos cívicos y no sobre Ventura, porque lo 
que ha sido expuesto en el MuAC no ha sido a un artista, sino una pieza.

A pesar de décadas de crítica de arte, teoría del arte y filosofía del arte que han abogado por pensar la obra más allá de las intenciones del autor y de no reducirla subjetivistamente al discurso no-dicho, velado, escondido y metaforizado de un sujeto-agente-causa del sentido, la lectura que se ha hecho de Cantos cívicos no tiene tanto que ver con la obra como con el autor.

Y esto abre distintos temas a la discusión. Pero nos parece que es importante insistir en que no se trata de juzgar la intención del autor, sino la obra. No es lo mismo y no hay que confundir la obra con el autor, si fuesen intercambiables podríamos ahorrarnos la visita al museo y simplemente preguntar a cualquier autor qué opina del mundo, del amor, del arte, de la tecnología, y demás temas que suelen aparecer en los fenómenos estéticos. Pero poco interesa lo que Ventura diga, mucho interesa, sin embargo lo que Cantos cívicos dice.

Ahora bien, ¿qué dice? ¿Qué interpretación de la obra puede ser pertinente y hacer justicia al desafío que ésta presenta? Por supuesto, las interpretaciones son innumerables y no es nuestra intención aquí hacer crítica de arte, sino reflexionar sobre algunos de los señalamientos que se han hecho sobre la pieza.

Uno de los temas que ha aparecido por doquier es el uso de la suástica en Cantos cívicos. La suástica es un símbolo, lo que nos conduce a preguntar: ¿Qué es un símbolo? ¿Cómo es posible usarlos con rectitud? ¿Cómo se resignifican? Estas preguntas emergen de cara a Cantos cívicos pues la obra conspicuamente juega con la recontextualización de símbolos clásicos para resimbolizarlos. El arte históricamente ha hecho eso. Los símbolos, no obstante, se resisten a ser insertos en una nueva red de sentidos, pero, como diría Ricoeur en el caso de la metáfora, "ceden resistiendo". Bien se podría 
afirmar que una de las tareas del arte es la resimbolización, y con ello el rompimiento de las expectativas de sentido de la espectadora. Cuando dichas expectativas se rompen, esto puede ser experimentado en términos positivos o negativos. La obra de Ventura ha realizado un rompimiento de las expectativas de sentido. ¿Significa eso que debe ser censurada o expulsada del MuAC? ¿Cuáles han sido y/o deben ser los criterios de censura? La Constitución Política de los Estados Unidos Mexicanos establece los casos en los que el Estado puede llevarla a cabo:

Artículo $6^{\circ}$. La manifestación de las ideas no será objeto de ninguna inquisición judicial o administrativa, sino en el caso de que ataque a la moral, los derechos de terceros, provoque algún delito o perturbe el orden público; el derecho a la información será garantizado por el Estado.

Artículo $7^{\circ}$. Es inviolable la libertad de escribir y publicar escritos sobre cualquier materia. Ninguna ley ni autoridad puede establecer la previa censura, ni exigir fianza a los autores o impresores, ni coartar la libertad de imprenta, que no tiene más límites que el respeto a la vida privada, a la moral y a la paz pública. En ningún caso podrá secuestrarse la imprenta como instrumento del delito.

Sobra decir que la ley mexicana es ambigua y al mismo tiempo está desactualizada en estos temas. Ahora bien, el problema que presenta Cantos cívicos difícilmente se puede abordar a partir de la ley mexicana. Lo que toca no tiene que ver con vida privada, moral o paz pública, sino con crímenes de lesa humanidad. No hay dentro del cuerpo de la Constitución Mexicana ninguna ley que hable al respecto, ${ }^{1}$

I. Aunque México firmó en 1966 un tratado multilateral que tiene como depositario a la Organización de la Naciones Unidas sobre discriminación racial y que, como todo acuerdo internacional de este tipo, queda reconocido como parte de la Ley Suprema de toda la Unión, el Artículo I 33 de la Constitución aclara que los tratados internacionales son parte de esta Ley siempre y cuando estén de acuerdo con la misma. Hay un peligro que ese condicional podría acarrear y es 
e incluso aquí no ha aparecido la polémica — ya superada en otros países- entre libertad de expresión y llamado al odio y discriminación. Sólo como referente es posible mencionar la llamada Ley Gayssot en Francia que sanciona la provocación al odio y la discriminación y específicamente prohíbe el "negacionismo". ${ }^{2}$ La ley ha despertado muchas discusiones sobre la libertad de expresión y la libertad de prensa, que llevan siempre incluido el cuestionamiento de ¿hasta dónde puede llegar la libertad de expresión, se puede decir lo que sea? En México incluso el debate ha rehusado transitar por allí. Por ejemplo, hace unos años la canción del grupo Molotov sobre el "gringo puñetero"3 debió haber dado qué pensar en términos de discriminación y llamado al odio, pero la polémica nunca se levantó.

Censurar la obra Cantos cívicos por las interpretaciones que de ella hubo parece en este contexto estar fuera de discusión. Hay que reflexionar entonces qué se sigue del rompimiento que hace la pieza de las expectativas de sentido. Si no las rompiera presentaría, por ejemplo, cualquiera de las imágenes multicitadas sobre el nazismo y la suástica aparecería en el contexto usual. No obstante, presentar algo distinto a lo mil veces ya visto conlleva el riesgo del rechazo y la incomprensión. ¿De hecho, rompe Cantos cívicos con las expectativas de sentido, y si así fuera, con cuáles?

Habría dos niveles de abordaje de la pieza: estético y sociopolítico; sostengamos esto por un momento. Estéticamente la obra no dice nada o dice poco, es una repetición de temas

precisamente aquél del riesgo — que sabemos toda ley supone - de interpretación múltiple y que podría acotarse de incluirse en la Constitución de los Estados Unidos Mexicanos, independientemente de este tratado multilateral. Pero además, significaría una toma de posición mucho más radical por parte de México que lo situaría dentro de las preocupaciones internacionales por estos derechos sociales y, más específicamente, humanos.

2. El término "negacionismo" se usa para aludir a la corriente que niega que el Holocausto haya tenido lugar.

3. De la canción "Frijolero" del disco Dance and dense denso (2003).

\section{2}


del arte presentados desde hace décadas en el panorama internacional. Incluso hubo cierto descuido en la exposición. Lo grotesco tampoco está bien logrado, no basta presentar fotografías de excrementos para lograr un efecto de sentido grotesco, se tiene que generar toda una composición estética, la cual es poco afortunada en la obra de Ventura. Generar asco en quien especta es muy sencillo, pero hacer algo en términos estéticos con eso es precisamente lo que el arte alcanza. No es, sin embargo, el caso en Cantos cívicos y no lo es porque no basta pegar una fotografía de un excusado junto a un oficial de la ss para decir algo.

Es lo mismo que sucede con la crítica al mundo del arte y a la alta sociedad mexicana. Ni lo kitsch ni lo irónico son sugerentes en Cantos cívicos, es demasiado obvio, es poco agresivo en la interpretación. En todo caso, no queda clara la relación que se pueda establecer entre los paisajes bucólicos, la denuncia a las prácticas de los museos, las ratas y el nazismo; esto es, no es clara la relación que la obra pretende instaurar entre tópicos tan diversos y cuya presentación en un mismo nivel de configuración resulta ofensiva, por decir lo menos.

Sociopolíticamente la obra no es neutra; no hay neutralidad ni ingenuidad cuando se representan suásticas. La crítica debe ser contundente y manifiesta, pero eso no sucede en Cantos cívicos. Que no suceda tampoco quiere decir que aparezca rampantemente una apología, de hecho está muy lejos de eso. En todo caso, diríamos que está lejos de ambas cosas: no hay una crítica directa y certera, y tampoco hay una apología. La pieza está mal lograda en su intención, y aun cuando se quisiera defender las virtudes de la ambigüedad en el arte —que abre así un espacio para la polisemia y la diseminación del sentido- no es esto lo que ocurre con Cantos cívicos. Dejar espacios abiertos de indeterminación para la interpretación es un logro de la composición estética; sin embargo, presentar las cosas sin contexto y puestas 
así delante sin más, es tan sólo el resultado de una mala configuración artística.

Hablemos un poco de los símbolos que en Cantos cívicos pretenden aparecer recontextualizados. No cualquier elemento funge como símbolo. La suástica es claramente un símbolo. Las ratas también, pero ¿de qué? Los símbolos pueden y de hecho aparecen en múltiples contextos. En su artículo Firma, acontecimiento y contexto de 1971, Derrida dice: "Todo signo [...] puede romper con todo contexto dado, engendrar al infinito nuevos contextos, de manera absolutamente no saturable" (Derrida, 2003: 361-362).

Ahora bien, algunos críticos han señalado que la suástica y el nazismo no pueden ser símbolos del neoliberalismo y que incluso sugerirlo es ya quitarle parte de su determinación y especificidad. No se pueden comparar los crímenes de Estados Unidos en Irak con los crímenes que la Alemania nazi cometió contra los judíos. No es lo mismo, y ello por un sinfín de razones, entre ellas y la más evidente el campo de exterminio. ¿Cómo emplear entonces la suástica?

En esto la estética filosófica presenta líneas de argumentación. Lo que aparece en el arte no aparece tal cual, sino metaforizado, es decir, aparece de otro modo a como antes era y desde ese momento puede aparecer con un sentido que toma distancia del "original". No se puede pretender que la cama pintada por el pintor en el cuadro sirva efectivamente para dormir. La cama está ahí de otro modo. Lo que el arte presenta está ahí de otro modo. Es labor de la interpretación descifrar-inventar en qué modo. Si la cama está de otro modo, ¿no lo estaría también el retrato del oficial de la SS, las suásticas, etcétera?

¿Hasta dónde puede permitirse el imaginario poético resignificar, resimbolizar y recontextualizar lo previamente dado? ¿Hasta el límite de la ofensa moral? Si el tema fuera religioso, nuestra calidad de librepensadoras y universitarias nos haría muy probablemente rechazar cualquier 
crítica e intento de censura, pues si la virgen María aparece de otro modo en el arte no debe significar ninguna ofensa para el creyente, sino la posibilidad del arte de dar otros sentidos; sin duda alguna diríamos esto. Sin duda alguna, también, un gran número de creyentes no coincidiría y sentiría su moral directamente ofendida, pediría, entonces, la censura de la obra porque ofende.

Las críticas a la pieza relacionan directamente el cuestionamiento del nazismo con el Holocausto, como si no se pudiera hablar de una cosa sin la otra, como si la asociación fuera moralmente necesaria para quien se refiere al tema. Poco comprende en esto la crítica de la historia del arte, de la historia de la representación del Holocausto y la polémica que en torno a su irrepresentabilidad ha habido, y del arte mismo; no queda claro por qué una obra artística tendría necesariamente que, como por una especie de mandato, hacer referencia al Holocausto para poder presentarse como una crítica al nazismo.

Pero sobre todo, ¿por qué habría que censurar o calificar de indigno para la Universidad Nacional Autónoma de México el albergar una pieza porque el corte en su crítica no estuvo hecho en el lugar "correcto" para que la pieza pueda ser claramente y sin lugar a dudas una puesta en cuestión del nazismo?

Si bien es cierto que hay elementos en esta instalación donde la crítica no está bien lograda, esa no es razón para que se la califique de indigna para la Universidad ${ }^{4}$ y mucho menos para pedir que se retire del Museo. Esto es, si la crítica que la pieza pretende no ha sido célebre y en muchos aspectos estéticos la obra tampoco, ¿qué se sigue de eso? ¿Su indiscutible retiro del recinto universitario? El juicio

4. El escrito "Cantos nazis" (I0 de febrero de 2009) de Enrique Krauze puede consultarse en http://cantoscivicos.blogspot.com y también en el blog de redacción de Letras Libres. 
que condena el buen arte o el mal arte no parece tener la fuerza suficiente como para demandar el retiro de una pieza, pero el juicio que condena moralmente sí. ¿Qué es lo que está aquí puesto en juego?

Lo que hay que resaltar es la polémica y el diálogo al que esta exhibición ha llevado dentro de la comunidad universitaria y fuera de ella. Como le dice Derrida a Roudinesco en la entrevista titulada Acerca del antisemitismo venidero:

Por cierto, ambos nos inquietamos ante tal o cual publicación. A resguardo de un "como si" cubierto por alguna ética de la literatura, hasta por un derecho indiscutible a la literatura, tal publicación está autorizada a propagar un lenguaje cuyas premisas y consecuencias más probables conocemos, que a nuestra manera de ver son las peores. Inculta o no, tal "literatura" inculca y halaga, responde a una ideología que consideramos nefasta y combatimos, por ejemplo el racismo o antisemitismo. Pero también aquí, más vale, creo, no prohibir. Más vale replicar (en ocasiones con el desdén merecido, con el silencio, eso depende del contexto y el peligro real) a contraatacar, analizar, discutir, evaluar, criticar, ironizar (Derrida y Roudinesco, 200I: 140).

Hay que insistir en esto, Cantos Cívicos es una pieza de arte (el juicio de gusto no lo pondremos aquí en juego) y por ende no puede ser juzgada igual que un discurso político o filosófico. El arte dice "de otro modo" y en ese decir distinto pide ser comprendido e interpretado también "de otro modo". Hay que poner en pie la interpretación de la obra y comenzar por señalar que no hay un discurso directo ni una referencia directa, una y otra cosa son en buena medida producto de la interacción entre el texto y la lectora. ¿La referencia de Cantos cívicos es el nacionalsocialismo, el Holocausto, el neoliberalismo, el mundo del arte? ¿Todos o ninguno de los anteriores?

¿Hay un llamado al odio racial y a la violencia en la obra de Ventura? No lo consideramos así. En todo caso hay un 
mal uso de la ironía, lo escatológico y lo grotesco que hace que la pieza no sea del todo exitosa ante la pretendida crítica o al menos no sea lo suficientemente provocadora. Pero ante una crítica fallida a los regímenes totalitarios nos parece más importante permanecer en la denuncia y polémica que optar por la censura; pues, de hecho, no censurar la obra sino exponerla manifiestamente abre la discusión, mientras que la censura la extingue. Eso, sin embargo, no redime de toda responsabilidad legal y moral al autor para con su obra; pero no es Ventura el que se encuentra aquí en juicio, sino la pieza.

La Universidad Nacional Autónoma de México está obligada a albergar todo el conocimiento científico, humanista o artístico que los miembros de su comunidad consideren oportuno. Es responsabilidad de las profesoras e investigadoras que en ella trabajan acompañar a las estudiantes y al público que la visita en la difícil y a veces hasta dolorosa tarea de interpretación y asimilación de ese conocimiento.

Esto no se trata sobre Ventura, pero, en todo caso si quisiéramos saber lo que él como persona común y corriente opina, en el Blogspot de Cantos Cívicos ${ }^{5}$ señala que para él el nazismo es una cuestión hasta cierto punto actual y define su obra como "a plausible fictional scenario" donde existe una continuidad del nazismo a nuestros tiempos." Dice también en la larga entrevista publicada en el libro sobre Cantos Cívicos:

[...] mi proyecto no es para nada una apología del nacionalsocialismo; al contrario, lo que me interesa es desenmascarar la hipocresía que hay alrededor de estos hechos, en esta condena al nazismo, como si éste fuera un episodio que pasó en la historia y que no entendemos cómo condujo a un desarrollo tan brutal. Pero el nazismo forma parte de una estructura occidental capitalista que se da en diferentes formas hoy día,

5. Disponible en: http://cantoscivicos.blogspot.com. 
quizás no en un campo de concentración, aunque todos sabemos que obviamente también los hay (Cantos cívicos, 2008: 142).

No obstante que las declaraciones de Ventura muestran el desconocimiento del autor sobre la historia y la poca responsabilidad que ha tenido al presentar una obra de temas tan sensibles con tan poco entendimiento sobre los acontecimientos, resulta interesante que la pieza se presente como una denuncia de los regímenes totalitarios y, en específico, del papel que la propaganda nacionalista tuvo y tiene en las organizaciones políticas. ${ }^{6}$

El señalamiento que hace aquí Ventura nos recuerda la película futurista Children of men (2006) dirigida por Alfonso Cuarón que se desarrolla cuando la humanidad ha perdido su posibilidad de reproducción. Lo que parece importante rescatar en este contexto es que, como telón de fondo de un Londres desgarrado por la violencia y los enfrentamientos entre sectas nacionalistas, se muestra la inmigración que por razones económicas han tenido que emprender los habitantes del sur del continente a los países del norte de una manera mucho más dramática que en la actualidad. Inglaterra, en esta película, ha decidido encerrar a todos los inmigrantes en campos de concentración parecidos a los que el nazismo "construyó". ¿Por qué no se puede leer esta profusión de signos entre nazismo y neoliberalismo que el artista hace a partir de la unión de suásticas y signos de divisas de países del llamado G8 como un llamado a las posibles consecuencias nefastas que el proyecto económico neoliberal puede estar engendrando?

Aunque reconocemos que hay que poner en cuestión si al nacionalsocialismo se le pueda calificar también de

6. No hay que olvidar que el nacionalsocialismo fue un proyecto de exterminio que se escondió bajo el manto de un programa económico y político y en donde incluso fue el argumento económico uno de los principales utilizado en la propaganda nazi para justificar la necesitad de expulsar y aniquilar judíos. 
régimen totalitario, lo que es cierto es que el totalitarismo necesaria e inevitablemente engendra y promueve de una manera violenta discriminación, segregación, exclusión e incluso aniquilación. Y aunque las consecuencias en uno y otro proyecto son inconmensurables, nos parece que la suástica bien puede remitirnos a una reflexión en torno a esos peligros sociales y ético-políticos. Nos parece interesante y productivo que la suástica pueda ahora provocar un análisis reflexivo en torno a todo tipo de exclusión. No condenamos ese uso mientras el Holocausto y el exterminio en general no se nieguen. Es factible leer Cantos cívicos como un llamado de atención frente a las posibles consecuencias atroces e incluso crímenes contra la humanidad que otras formas de totalitarismo pueden ocasionar, pero cabe resaltar que con esto no estamos afirmando que el nazismo pueda ser comprendido como uno más de los regímenes totalitarios, porque no lo fue.

Por otro lado, es importante tomar en cuenta - y sólo por seguir hablando de lo dicho por Ventura-, que lo que vemos en Cantos cívicos es una especie de cueva en la que habita un personaje obviamente ficticio. Aclaramos esto porque Krauze, en su escrito publicado en Letras Libres dice que al internarse en la instalación él penetró al mundo de Ventura, y se equivoca. No se entra en el mundo del autor, sino de la obra; el mundo interior del autor no está allí presente para quien especta con intenciones estéticas y no psicoanalíticas. ¿Qué quiso decir Ventura en Cantos cívi$\cos$ ? ¿Qué le hizo a Ventura crear un mundo así? Esos son problemas o preguntas aptos para la clínica psicoanalítica y no para la crítica de arte.

El mundo de Cantos cívicos es ficcional y está mediado por otra ficción que es la del Nuevo Consejo Interterritorial de Lenguas (NILC, por sus siglas en inglés). En esta pieza, pues, encontramos dos mundos ficcionales, uno dentro del otro. Así como no nos atreveríamos a acusar a los hermanos 
Cohen de asesinos múltiples o sociópatas por el personaje de Anton Chigurh de su película No Country for Old Men (2007), ${ }^{7}$ no podemos tampoco juzgar de antisemita al autor de esta pieza.

Citando nuevamente a Derrida: "No bien hay 'literatura' (si la hay, y que sea pura), el 'yo' que toma la palabra permanece, desde el punto de vista del derecho, en posición del 'yo' ficticio. No compromete al autor o al firmante real, como sujeto del derecho. El autor puede hacerle decir o dejarlo decir cualquier cosa, sin caer, en principio, bajo el peso de la ley" (Derrida y Roudinesco, 2001: 141). Siendo así, ¿por qué la exigencia de que en la pieza se vea el dolor del Holocausto? ¿Qué y cómo hablar del Holocausto?

Ahora bien, no es seguro que el punto aquí sea discutir el Holocausto. No es el punto aquí y tampoco en Cantos cívicos. Ciertamente se dice con justicia que no es posible hablar del nacionalsocialismo sin hablar del Holocausto. Pero existen distintos contextos para abordar las cosas, y el arte a menudo genera sus propios contextos de significación. Se le puede nombrar indirectamente, de modo no manifiesto, como una alusión. Muchos autores, por ejemplo Claude Lanzmann y su filme Shoah, señalan que, de hecho, sólo se le puede aludir, porque lo allí sucedido es literalmente irrepresentable. $^{8}$

Y para este amplísimo debate también se pueden mencionar los relatos testimoniales y el modo en que han trabajado la experiencia concentracionaria, el horror del nazismo, etc., de Primo Levi a Charlotte Delbo.

Juguemos con poner en pie una interpretación, entre otras muchas. La estructura física de la obra remite al acecho de lo subterráneo. Ese acecho al que se debe prestar

7. Basada en la novela del mismo título del escritor estadounidense Cormac McCarthy.

8. Georges Didi-Hubermann discute ampliamente el tema en Imágenes pese a todo: Memoria visual del Holocausto.

\section{0}


voz, mirada y oído pues aunque no lo vemos ni escuchamos está ahí y produce efectos. Se trata de una cueva, pero el video que se presenta justo a la entrada de la instalación muestra una especie de acercamiento al estilo de las novelas de Balzac tamizado por Google Earth en el que del espacio se ve la silueta de México en la Tierra, luego se va acercando hasta el Distrito Federal, de ahí a Ciudad Universitaria hasta el MuAC. Se trata entonces de una cueva dentro de una cueva dentro de otra cueva. La creación de este espacio como bunker ${ }^{9}$ hace pensar en cómo lo subterráneo, cómo aquello que está o ha sido velado, resulta fundamental cuando se trata de una reflexión sobre el totalitarismo, pues la exclusión, persecución, aniquilación, etc., de un régimen de esta naturaleza puede hacerse desde el silencio o desde el escándalo. Quizá sea lo subterráneo uno de los temas más interesantes que surge a raíz de esta pieza, pues si bien es cierto que el régimen nacionalsocialista con Hitler a la cabeza cometió crímenes que uno ni siquiera podría imaginar y que los cometían abiertamente, hubo muchos otros de los que hemos ido sabiendo con el paso del tiempo.

Lo que sostenemos es la importancia de permitir que un signo diga y denuncie cosas nuevas que no por eso son inéditas. Hay otros regímenes que con sus políticas económicas neoliberales, por ejemplo, matan de hambre a millones de habitantes del planeta Tierra y los obligan a vivir en condiciones inaceptablemente crueles. Ahí es donde puede verse lo subterráneo de los crímenes de estos países,

9. En la entrevista a Miguel Ventura realizada por Cecilia Delgado que aparece en el libro de Cantos Cívicos (véase nota 4) el artista menciona que sí estuvo en su mente una referencia a la película La caída (Der Untergang, 2004) dirigida por Olivier Hirschbiegel donde se narran los últimos días de la vida de Adolf Hitler recluido en un bunker. Dice: "Castellón fue bombardeada por los franquistas durante la Guerra Civil y eso me llevó a la idea de las guaridas secretas de estos personajes turbios, y que inmediatamente relacioné con esta película alemana sobre los últimos días de Hitler, escondido en un bunker como si fuera una ratonera" (p. 124). 
grandes potencias económicas y políticas que a veces de una manera un tanto velada y otras manifiestamente llevan al aniquilamiento de otros. ¿Cuántos millones de personas no tienen acceso a la comida en este planeta? ¿Cuántos millones viven en condiciones donde su vida no es digna de vivirse, como dice Derrida? Y muchos de estos desastres y crímenes contra seres humanos han sido ocasionados por políticas económicas equivocadas, por decir lo menos. No han dicho George W. Bush o Felipe Calderón, por mencionar sólo a dos, que éstas sean consecuencias que tienen ya calculadas por sus políticas neoliberales, pero ¿qué son entonces? ¿"Daño colateral”? ¿Podría el término "crimen de lesa humanidad" abarcar estas atrocidades? ¿Por qué no puede pensarse así? 8

Fecha de recepción: 23 de junio de 2009. Fecha de aceptación: 7 de octubre de 2009.

Bibliografía

Cantos Cívicos. Un proyecto de NILC en colaboración con Miguel Ventura (2008), México, Universidad Nacional Autónoma de México.

Derrida, Jacques y Elizabeth Roudinesco (200I), “Acerca del antisemitismo venidero”, en Y mañana qué..., Argentina, FCE.

Derrida, Jacques (2003), "Firma, acontecimiento, contexto", en Márgenes de la filosofia, España, Cátedra. 